\title{
Teacher subject matter knowledge for the meaningful transition from arithmetic to algebra
}

\author{
Pınar Yıldız and İ. Elif Yetkin Özdemir² \\ ${ }^{1}$ Çanakkale Onsekiz Mart University, Turkey (ORCID: 0000-0002-6729-7721) \\ ${ }^{2}$ Hacettepe University, Turkey (ORCID: 0000-0001-8784-0317)
}

\begin{abstract}
Teacher knowledge is particularly important in middle school mathematics to enhance the meaningful transition from arithmetic to algebra. Developing a solid understanding of algebra requires teachers to unpack the meaning underlying the basic concepts, make clear and explicit distinctions among concepts, and facilitate students to connect these concepts with their prior knowledge and understandings in arithmetic. This study focused on the content knowledge (i.e., decompose, trim, and bridge) of three middle school mathematics teachers in practice during the introduction of basic algebra concepts (i.e., variable, algebraic expression, equality and equations). Case study was used as research design in this research. Individual interviews and observations regarding the instructions were used to gather data. Results showed that the participating teachers' conceptions regarding the variable, algebraic expression and equation were rather narrow and it resulted in several constraints when unpacking their meaning in the classroom. While bridging was a commonly observed instructional practice among the participating teachers, the quality of bridging, did not always provide opportunities for a meaningful transition. Trimming, on the other hand, was not observed as a common teaching practice.
\end{abstract}

Keywords: Algebra; Algebraic expression; Equality and equation; Teacher knowledge; Variable

Article History: Submitted 10 July 2021; Revised 19 December 2021; Published online 31 December 2021

\section{Introduction}

Students construct algebraic notions based on their previous experience in arithmetic (Booth, 1988; Brizuela, 2016; Christou \& Vosniadou, 2012; Kieran, 1992). Equations requiring relational thinking, word problems beginning with unknown values, symbols and shapes, and verbal statements that represent mathematical relationships provide opportunities for students to develop algebraic thinking. For instance, engaging with number sentences (e.g., $13=6+7=5+8=4+9$ ) helps students develop relational thinking and they better understand how to preserve the equality when solving equations with unknowns. Likewise, making connections with verbal statements representing mathematical relations (e.g., each car has four wheels) helps students understand that variables can also represent varying quantities. That is, students can develop understandings for fundamental concepts and ideas of algebra as they engage with arithmetic tasks.

Address of Corresponding Author

Pınar Yıldız, PhD, Çanakkale Onsekiz Mart University, Anafartalar Campus, 17000, Çanakkale, Turkey.

$\triangle$ akdalpinar@gmail.com

How to cite: Yıldız, P. \& Yetkin-Özdemir, İ. E. (2021). Teacher subject matter knowledge for the meaningful transition from arithmetic to algebra. Journal of Pedagogical Research, 5(4), 172-188. https:// doi.org/10.33902/JPR.2021474587 
This study focused on three fundamental concepts (variable, algebraic expressions and equations) in basic algebraic thinking. The concept of variable represents a critical point of algebraic thinking and the transition from arithmetic to algebra (Blanton et al., 2017; Brizuela et al., 2015; Knuth et al., 2016; Stacey \& MacGregor, 1997). Developing a solid understanding of variable and equality is closely related to how students conceptualize algebraic expressions and equations (Blanton et al., 2018; Kuchemann, 1978; Usiskin 1999; Weinberg et al., 2016). Research, however, has shown that many students are unable to construct a good intuitive basis for the ideas of algebra or to connect these with the pre-algebraic ideas developed in primary school (Blanton et al., 2015; Brizuela, 2016; Christou \& Vosniadou, 2012). Hence, they fail to construct meaning for the new symbolism and are forced to perform operations on symbols without understanding (Herscovics \& Linchevski, 1994). We argue that developing algebraic understanding essentially depends on developing meaningful transitions from arithmetic to algebra. Making connections between pre-algebraic concepts that students have developed in primary school with basic algebraic concepts (e.g., variable, algebraic expressions, equations) is essential especially in middle school mathematics. This brings the question of what teachers need to know in order to facilitate such transition.

\subsection{Literature Review and Theoretical Framework}

Researchers indicate that teachers' subject matter knowledge influence their teaching practices (Copur-Gencturk, 2015; Hoover et al., 2016; McCrory et al., 2012; Spangenberg, 2021) and therefore affect student acquisition in algebra (Even, 1993; Huang \& Kulm, 2012; Tchoshanow et al., 2017; Wasserman, 2015). Subject matter knowledge for teaching mathematics includes (a) common content knowledge (i.e., mathematical knowledge and skills that are not specific to teaching) and (b) specialized content knowledge (i.e., knowledge of different forms of representation of mathematical contents and explanations of mathematical rules and procedures that are specific to teaching mathematics) (Ball et al., 2005; Ball et al., 2008; Hill \& Ball 2004; Hill et al., 2008). The mathematical knowledge required to solve an equation with one unknown could be considered as an example for the common content knowledge. On the other hand, knowing that the different ways to solve a system of linear equations with two unknowns (e.g., elimination method, substitution method, graphing) are related to each other could be considered as an example of specialized content knowledge.

Building on the work of Ball and others, McCrory et al. (2012) emphasized the importance of how knowledge is used in teaching practices. They defined three categories to describe teacher knowledge in practice: (a) decompressing, (b) trimming and (c) bridging. Decompressing involves unpacking mathematical knowledge so that the fundamental components are more explicit and accessible to the students (Ball \& Bass, 2000a; Cohen, 2004 as cited in McCrory et al., 2012). Decompressing requires teachers to "separate advanced concepts from their precursors" (McCrory et al., 2012, p. 603). With regard to teaching algebra, decompressing may involve making different meanings of letter symbols explicit for students or explaining in detail why algorithms for solving equations work. Decompressing also involves careful use of words that have multiple meanings and implications in mathematical discourse. For instance, referring variables as "unknowns" in equations and "varying quantities" in algebraic expressions help students understand different meanings of letter symbols. Another category of knowledge in practice is trimming, which involves intentionally adjusting the content (i.e., adding details or omitting, scaling up and down) and recognizing instances when important details or cases are missing. Trimming also involves anticipating and taking into account related mathematical concepts and ideas that students will encounter later. Calling students' attention to the fact that the values satisfying a given equation depend on the set being worked on (e.g., $\mathbb{N}, \mathbb{Z}, \mathbb{R}$ ) could be considered as trimming. Bridging, on the hand, refers to making connections between mathematics across topics, courses and other disciplines. That is, bridging involves efforts to show students "the big picture of mathematics, making explicit connections across topics, keeping a range of ideas in play in the classroom, and 
presenting mathematics as a coherent, connected endeavor" (McCrory et al., 2012, p. 608). With regard to developing algebraic thinking, bridging may involve grounding students' algebraic understanding to their understanding of arithmetic, that is, the structure and properties of number systems and operations.

Research has mostly focused on examining teacher knowledge on algebra through tests, tasks, or interviews (Caswell, 2009; Çelik \& Güler 2018; Dooren et al., 2002; Li, 2007; Reckase et al., 2015; Stephens, 2008; Stumps \& Bishop, 2002; Watkins, 2018). Such research has shown that teachers have limited knowledge and understandings of basic algebraic concepts such as variable, equality, algebraic expression and equation. Teachers generally define algebra as "use of letters and symbols". They lack a relational understanding of equal sign and do not use algebraic relations in concepts and processes. They mostly focus on operational knowledge and cannot make conceptual explanations of operational processes.

\subsection{The Aim}

While earlier research has documented that teacher knowledge on algebra is limited, very little is known about teachers' knowledge and skills on the transition from arithmetic to algebra and in particular, the knowledge that they use in teaching practices. This study aimed to explore three middle school mathematics conceptions of basic algebra concepts, i.e., variable, algebraic expression, equality and equations that play essential roles on the transition from arithmetic to algebra. Ball et al. (2008)'s framework was used in this study to describe dimensions of teachers subject matter knowledge related to these concepts: (i) knowledge of mathematical symbols and terms, (ii) knowledge of definitions, procedures and concepts, (iii) knowledge of different types of representations and explanations, and (iv) knowledge of selecting and using representations, definitions or explanations. On the other hand, McCrory et al.'s (2012) framework was also utilized to examine whether and how the participating teachers used their knowledge in teaching practices (i. e., decompose, trim, and build).

\section{Method}

\subsection{Research Design}

Understanding teachers' mathematical knowledge requires a detailed and holistic examination of the teaching process. Qualitative research focuses on context and provides a wealth of information about it (Creswell, 2007; Denzin \& Lincoln, 2000; Yin, 2009). For this reason, a case study design was employed in this study.

\subsection{Participants}

Three middle school mathematics teachers employed at public schools participated in this study. The study addressed each teacher as a case and their teaching practices were examined in detail. Convenience sampling and criterion-sampling methods were used to select the participants. Conducting mathematics courses at the $6^{\text {th }}$ grade level was identified as a criterion since the algebra concepts examined in this research were related to this grade level. Teachers who aspired to share her/his ideas and felt confident about being observed were selected from among the $6^{\text {th }}$ grade teachers who were reached by the researchers and who volunteered to participate in the study. Ayla, Hale and Emre (pseudonyms) had 2, 3 and 8 years of teaching experience, respectively. All teachers worked in the boundaries of the same mid-sized city located in the Central Anatolia, Turkey: Ayla was teaching in a village and Hale and Emre were teaching in the same school in the city center. The socio economical levels of both schools were average.

\subsection{Data Collection Procedure}

Data were collected using individual interviews and in-class observations. In-class observations aimed to investigate teachers' knowledge of algebra in detail through their teaching practices. A total of 10 lesson hours at $6^{\text {th }}$ grade classrooms were observed for each teacher as they taught 
patterns and relations, algebraic expressions, equality and equations. According to the Middle School Mathematics Education Program in Turkey, teachers are expected to allocate two lesson hours for patterns and relations, two hours for algebraic expressions, and six hours for equality and equations. Class observations focused on teachers' definitions of concepts, explanations, examples and the mathematical representations they used. Field notes were taken to describe the classroom context and teacher-student interactions in more detail. The observed lessons were recorded with a video recorder.

Three semi-structured interviews (pre-interview, first interview, second interview) were conducted. First and second interviews were conducted after classroom observations. All the interviews were recorded with a voice recorder. The pre-interview aimed to get to know the teachers and to establish rapport. The purpose of the first interview was to collect data about teachers' knowledge of algebra. During the second interview, teachers were presented with teaching scenarios and asked questions about the scenarios as well as the instances observed in their teaching practices. Teaching scenarios were developed after a detailed investigation of relevant literature (Asquiths et al., 2007; Behr et al., 1980, Booth, 1988; Knuth et al., 2008; Falkner et al., 1999; Kieran, 1981; Kuchemann, 1978; Usiskin, 1999). Two experts checked the content and the language used in questions to ensure reliability and validity. Some examples from the interview questions used in this study are presented below.

- Algebra is considered as an important topic in middle school curriculum. Do you agree with this idea? (If yes) Why? (If no) Why not? (Interview I)

- One of the fundamental concepts of algebra is "variable". Why do you think it is important to understand variable (in terms of learning mathematics)? (Interview I)

- The sixth grade mathematics teacher, Ms. E, asked the following question to her students about equality and equations.

In the expression $8+4=\square+5$, what number should replace $\square$ ?

In your opinion, why Ms. E asked this question? (Interview II- Teaching scenario)

\subsection{Data Analysis}

Based on the framework developed by Ball et al. (2008), this study focused on the four dimensions of teachers' subject matter knowledge: (i) knowledge of mathematical symbols and terms, (ii) knowledge of definitions, procedures and concepts, (iii) knowledge of different types of representations and explanations, and (iv) knowledge of selecting and using representations, definitions or explanations. For instance, the symbols (e.g., algebraic letters) and definitions used by the teachers while explaining or teaching the concept of variable were examined in the study. Likewise, the representations (e.g., balance scale, verbal statements, number sentences) they used to explain and teach equations were also explored. On the other hand, the framework of McCrory et al. (2012) was used here to describe teachers' subject knowledge in practice (decompressing, trimming and bridging). With the help of this framework, it was possible to examine whether or to what extend teachers used their subject matter knowledge to make the concepts and procedures more explicit for their students, to adjust the content for student exploration, or to show students a coherent and connected structure related to the concept. That is, the framework of Ball et al. (2008) was used to describe the dimensions of subject matter knowledge whereas the framework of McCrory et al. (2012) was used to describe uses of subject matter knowledge in teaching practices (see Table 1 for descriptions and sample practices).

Video and audio recordings of classroom observations (e.g., teacher explanations, examples and materials used, teacher-student dialogues) and interviews were organized and transcribed during data analysis. A data corpus for each teacher was created by combining data sets. Subsequently, transcription of observations and interviews were categorized according to the related concepts, i.e. variable, algebraic expression, equality and equation. The classified and encoded data were interpreted and associated with each other. Direct quotations from observations and interviews were presented. 


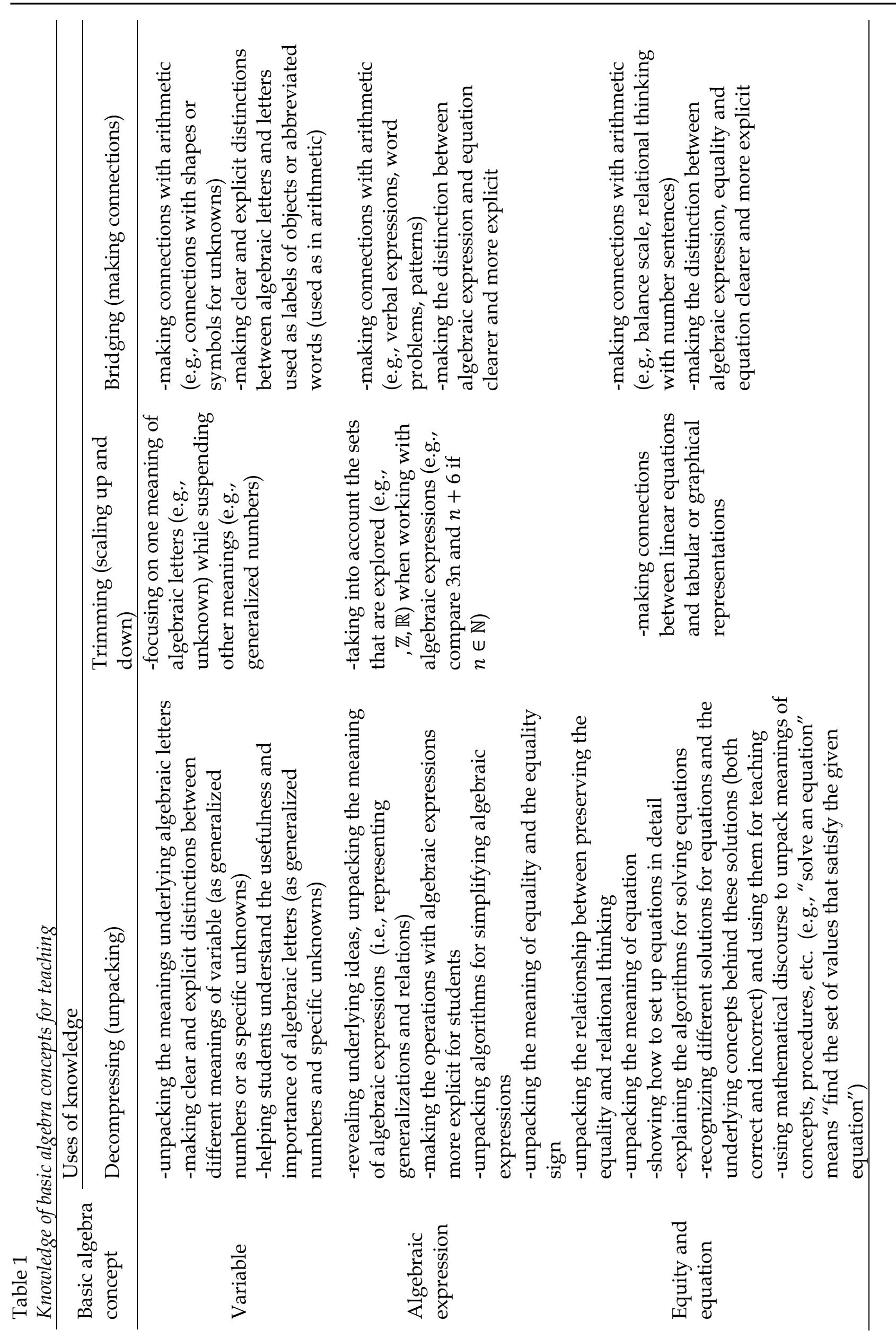




\section{Results}

This section presents the results under three headings: (a) knowledge of "variable" in teaching practices, (b) knowledge of "algebraic expression" in teaching practices, and (c) knowledge of "equality and equation" in teaching practices. Each heading includes the findings of teachers' subject matter knowledge (SMK) about the concept (i. e., knowledge of mathematical symbols, terms, definitions, procedures, concepts, different types of representations and explanations) and how teachers used their knowledge in teaching practices (decompressing, trimming and building). These themes that defined teachers' content knowledge and how they used their knowledge in teaching practices are indicated italic and in parentheses.

\subsection{Knowledge of "Variable" in Teaching Practices}

The term 'variable' is defined as "the letter symbols used to indicate one or more numbers" (Herscovics \& Linchevski, 1994, p.33). Basically, variables are used as unknown $(5 x-9=91)$, varying quantities $(y-9 x=2)$ or generalized numbers $(a+b=b+a)$ (Philipp, 1992). That is, the concept of variable is used with different meanings in different situations (Malisani \& Spagnolo, 2009), which may cause difficulty in understanding the concept. Therefore, the variable is one of the fundamental concepts that need to be unpacked. Teachers need to be aware of the different meanings underlying algebraic letters and make these differences explicit for their students.

In this study, it was found that teachers had knowledge about the different meanings of the concept of variable. When they were presented with the tasks (a. If $n$ is a natural number, which expression is bigger, $3 n$ or $n+6$ ? $\mathrm{b}$. If $\mathrm{a}$ is smaller than $\mathrm{b}$ and $a+b=10$, then what is $a$ ? $c$. If $x+2=2+x$, what are the values of $x$ ?) and asked the purpose of using them in teaching mathematics, they recognized and explained the distinctions between different meanings of the variable (SMK- knowledge of concepts).

They, however, did not explicitly focus on such differences in their instructional practices. They either implicitly mentioned various meanings for variable or sent conflicting messages that restricted students' understanding. For instance, they used the terms, "letter", "unknown" and "variable" interchangeably and did not take into account the different meanings and of roles they played (Decompressing- unpacking the meaning underlying algebraic letters, making clear and explicit distinctions between different meanings of variable). For instance, Ayla described variable as letter symbols that can take different values and did not make the different roles that algebraic letters play in equations, in algebraic expressions, and in algebraic identities more explicit (Classroom Observation-4 (CO-4)/Algebraic Expressions \& CO-5/Equality and Equations). Her explanation presented below also supports the finding that she did not take the different meanings of letter symbols into account:

"For example, the letters we use in mathematics, such as in algebraic expressions, in equations, are unknown, they are variable. For example, in the equation $a+3=5$, the letter a is an unknown, that is variable. For example, when we consider the identity $a^{2}-b^{2}=(a-b)(a+b)$, a and $\mathrm{b}$ may take different values. In other words, we can say that the variables are letter symbols that we can insert different values." (Ayla, Interview II)

On the other hand, Hale used the term "variable" in order to refer to "the letters used in algebraic expressions" (CO-3/Algebraic Expression) and "unknown" in order to refer to "the letters used in equations" (CO-5/Equality and Equation) (SMK- knowledge of concepts). Moreover, she often made the following statement while teaching: "The letters in algebraic expressions are variables; the letters in equations are unknown." She, however, did not explain explicitly why these letter symbols are called differently (Decompressing- unpacking the meaning underlying algebraic letters, making clear and explicit distinctions between different meanings of variable).

Hale: I keep stating that we call letters in algebraic equations as variable, and call the letters in equation as unknown. I say, in algebraic expression [it is] called variable, in the equation we call [it as] unknown. (Hale, Interview III) 
Hence, the distinction between letter symbols representing changing values (i.e., variables) and those representing unknown values was implicit in her instruction (Decompressing- unpacking the meaning underlying algebraic letters, making clear and explicit distinctions between different meanings of variable). The most explicit explanation was made by Emre as depicted below.

Emre: What are we going to do? Here we have an unknown [referring to $x$ in the equation: $2 x+15=45$ ]. When we are dealing with equations, we could find the value for $\mathrm{x}$. What if we don't have the part "equal to 45"? What would come for $\mathrm{x}$ ? Any number. Why? Because there is no value equal to it [referring to $2 x+15$ ]. Put 5 for $x$, for instance, $2.5+15=25$. That is, if we have an algebraic expression, $x$ could be any value. But if it is an equation, then $x$ could only take specific values. Because algebraic expressions are not equal to any value, I can put any value for $x$. But then I could find different results [for each algebraic expression]. (CO-5/Equality and Equation)

Even though Emre focused on the distinction between algebraic letters as unknowns in equations and as varying values in algebraic expressions, he also used the term "unknown" in order to represent the varying values in algebraic expressions. These conflicting uses of words may restrict students' understandings and access to different meanings and uses of algebraic letters. (Decompressing- unpacking the meaning underlying algebraic letters, making clear and explicit distinctions between different meanings of variable).

"We call the letters such as $x, y, z$ as unknown. How many unknowns are there $(4 x+3 a+7 z)$ ? Here what we call unknown is the letter." (CO-2\&3/Algebraic Expressions)

As teachers attempted to decompress the concept, we also observed misconceptions in their understanding. For instance, Ayla wrote two equations with the same letter symbol " $b$ " on the board. Then she called each " $b$ " as a variable because it could take different values in different equations (SMK- knowledge of mathematical symbols and concepts). A similar instance was also observed with Hale who had same intention. Even though teachers seemed to attract students' attention to a common mistake, their explanation demonstrated the flaw in their understanding. The quotation below illustrates Ayla's explanation.

Ayla: I wrote two equations $(b+1=5$ and $b-2=7)$. Here we called $\mathrm{b}$ as the variable, as the unknown. But what if we look at the first equation, what is $b$ ? $b$, in the first equation, is $4 . b$ equals 9 in the second equation. But, here is something you need to pay attention. For instance, $x$ was 5 in one example. The value of $x$ can change from problem to problem, okay? Because of this, we call $x$ is variable. Look at the first example; $b$ is 4 . In the second example there is $b$ again, but it is 9 at this time. Its value changed for each problem. $b$ doesn't have to be 10 or 5 all the time. (CO-9/Equality and Equation)

According to Kieran (1992), different uses of literal symbols in arithmetic (e.g., labels, entities) cause another difficulty. In arithmetic, students usually come up with letters such as " $m$ " to denote meters, monkeys, etc. That is, $12 \mathrm{~m}$ refers to 12 meters or 12 times 1 meter. But in algebra, $12 \mathrm{~m}$ means 12 times the number represented by the letter " $\mathrm{m}$ ". Research has shown that most students consider literal symbols as objects, labels of objects or abbreviations rather than entities standing for quantities (Kuchemann, 1978). Hence in order to make meaningful transition from arithmetic to algebra, there needs to be a clear distinction between literal symbols used as labels or placeholders and literal symbols that represent variable.

No teaching practices that focused on such distinction was observed in this study (Decompressing- unpacking the meaning underlying algebraic letters). On the contrary, the teachers themselves were observed to represent unknowns or variables as objects rather than numerical values (SMK- knowledge of mathematical symbols, terms and concepts). For instance, Ayla described the variable $k$ in $2 k+3 k$, as an object (pen) and said that "What about 2 pen plus 3 pen? 5 items" (CO-4/ Algebraic Expressions). Likewise, Emre used the terms pencil and notebook when referring to $x$ and $y$ in the algebraic expression $2 x+5 y-9$ (CO-3/Algebraic Expressions). These instances demonstrated the flaws in teachers' knowledge as they unpacked their understanding of the variable (SMK-knowledge of mathematical symbols, terms and concepts).

During observations, there was no instance showing that teachers decompressed the usefulness and importance of algebraic letters as generalized numbers and specific unknowns (Decompressing- 
helping students understand usefulness and importance of algebraic letters). Only Ayla made explicit connections between shapes and symbols that students used for unknowns in elementary school when she was introducing algebraic expressions in an effort to bridge with pre-algebraic concepts. None of the teachers made explicit connections between finding a general rule of number patterns and algebra. They did not take into account that working on number patterns could help students recognize a generalization and write it as an algebraic expression (Bridging- making connections with arithmetic). In fact, teachers thought that students could work on number patterns after they worked on algebraic expressions rather than introducing algebraic expression through number patterns. Such instances illustrated the missing opportunities for the transition from number patterns to algebraic letters as varying quantities and the idea of generalization in algebraic expressions.

\subsection{Knowledge of "Algebraic expression" in Teaching Practices}

Developing a solid understanding of variable is closely related to conceptualizing algebraic expressions. Teachers need to decompress the meaning of algebraic expressions (e.g., $3 a$ represents 3 times any number) as entities representing generalizations and relations. Making explicit connections with verbal expressions, word problems and patterns could facilitate students' transition to algebraic expressions based on their experiences with arithmetic. In this study, participating teachers disregarded the meaning of algebraic expressions as entities representing generalizations. They mostly focused on procedural aspects (SMK- knowledge of mathematical symbols, terms and concepts). For example, Emre defined algebraic expressions as "expressions containing at least one unknown and operations." All the teachers emphasized that there must be letters and operations in algebraic expressions (Decompressing-revealing underlying ideas, unpacking the meaning of algebraic expressions). Emre stated that "It is important for students to know that it is an algebraic expression when they see a letter and an operation." (Emre, Interview II)

Even though Hale mentioned that letters in algebraic expressions may take different values, she used the term "unknown" to refer the letter symbols in algebraic expressions. She emphasized that the students did not know the values of these letters (i.e., unknowns) and she disregarded the fact that those letters can take "any value." Hence, the idea that algebraic expressions are used for generalizations was still unexplained (Decompressing- revealing underlying ideas, unpacking the meaning of algebraic expressions).

Hale: Is $5 b+2$ an algebraic expression? If there is a letter in it, the letter means it is unknown. Then we call it algebraic expression. Is $8+2$ an algebraic expression?

Bahri: It is not algebraic, because there is no letter or anything different.

Hale: Yes, it is not an algebraic expression. If there [refers to 8+2] comes a letter, then each of them

becomes an algebraic expression. (CO-3/Algebraic Expressions)

Ayla introduced algebraic expressions by reminding students that they had used shapes for the unknown at elementary school. She however, focused on letters as representing unknowns and disregarded using letters to refer to "any" number (Bridging-making connections with arithmetic). Therefore, reminding students that they had used shapes to represent the unknown in elementary school did not support a meaningful transition to algebraic expressions. The following illustrates that instance:

Ayla: In elementary school, your teacher was showing operations. S/he, for example, put a square, said that, plus 2 is equal to $5 . \square+2=5$. What were you doing here? We were saying that which number added to 2 would be 5 . Now in algebraic expressions, they erase the square and put the letter " $a$ " instead...Let's erase and put " $b$ " instead of it. You can ask, why " $a$ " or " $b$ "? If you want, [you can] write $a, b$, or $x, y$. It does not matter. You need to know that $x, a$, or $b$ is an unknown, $a$ variable. If I use an operation with an unknown, I call it an algebraic expression. (CO-4/Algebraic Expressions)

Likewise, the following explanation of Emre "...That is, if there is a letter and operation it is an algebraic expression. Also, there is equality in equations." (Teacher Emre, Interview II) shows that 
he reduced the bridging between algebraic expressions and equations to the existence of equality (Bridging- making clear and explicit the distinction between algebraic expression and equation).

Disregarding the meaning of variable as varying quantities may cause students not consider algebraic expressions as entities. Tirosh et al. (1998) noted that students tended to conjoin or finish terms when they were asked to simplify algebraic expressions (e.g., $2 x+3$ as $5 x$ or 5). Students may think that algebraic expression is incomplete and tend to finish it. Booth (1988) stated that students' experiences in arithmetic, for example, their interpretation of the "+" symbol in terms of action to be performed may have also caused such mistakes. Conjoining of terms to denote addition does appear in arithmetic in mixed fractions (e.g., $2 \frac{1}{2}=2+\frac{1}{2}$ ) and in place value (e.g., $43=4$ tens +3 units) as well, which may lead students to mistakenly connect these situations (Matz, 1980). Hence it is important to help students become aware that " $2+3$ " represents not only a process (i.e., adding 2 and 3) but also a result which can be expressed in different ways (e.g., $1+4$ or 5 ). If this distinction is not noticed in the pre-algebra process, students may have difficulty in the transition from arithmetic to algebra (Booth, 1988).

In this study, participating teachers' conceptions of letter symbols as objects affected how they explained operations with algebraic expressions. In particular, they explained addition and subtraction in algebraic expressions by making object analogy. They described variables in algebraic expressions as objects such as pencil, book, apple or pear (SMK-knowledge of mathematical symbols, terms and concepts). Then, they explained why unlike terms could not be added or subtracted by referring to the common analogy that we cannot make addition between apples and pears. For example, Emre started the lesson by stating that addition and subtraction could only be conducted among similar terms. He explained that in the expression $9 x+8 x$, the terms $9 x$ and $8 x$ could be added because they contained the same letter symbol, on the other hand the terms $7 x$ and $8 y$ in the expression $7 x+8 y$ could not be added because they had different letter symbols. He, however, ended the lesson with an object analogy. In the algebraic expression of $2 x+5 y-9$, he made a pencil analogy for $x$ and notebook for $y$, and stated that they could not be added because there were different unknowns (Decompressing- making operations with algebraic expressions explicit for students, unpacking algorithms for simplifying algebraic expressions).

Emre: $x$ and $y$, here, are different concepts. $x$ is a different value, $y$ is a different value. What did we just say instead of $x$ ?

Students: Pen.

Emre: Let's call it is a notebook instead of $y .2$ pencils 5 notebooks, can I add them? Two unknowns are different. We cannot add them. (CO-3/Algebraic Expressions)

\subsection{Knowledge of "Equality and equation" in Teaching Practices}

Students' initial experiences with equality sign and equality begin in arithmetic. However, their prior experience with equality symbol in arithmetic is different compared to that of algebra, which can explain some of the difficulties students may encounter (Kieran, 1981). In students' arithmetic experience, equal sign is usually interpreted in terms of actions to be performed, so that " $=$ " means "to write the answer" (Booth, 1988). Hence, many students view the equal sign operationally when they begin middle school. However, in algebra, students must view the equal sign as a symbol showing a relation (i.e, the same as) rather than a symbol representing an operation (i.e., do something). Therefore, the underlying meaning of equality symbol showing a relation (the same as) needs to decompressed for an effective transition. Using balance scale or expressions such as $3+7=7+3, \square+4=8$ and $4+5=\square-1$ could help students understand relational thinking and view the equality sign as a relational symbol (Van de Walle et al., 2010).

In this study, participating teachers were found to associate the concept of equality with the balance scale (weighing scale) (Bridging- making connections with arithmetic). They defined equality as the state of balance for the scale (SMK-knowledge of concepts, definitions and different types of representations). Also, preserving equality was associated with balancing of the scale pans while adding and subtracting weight. Teachers verbally explained the concept of equality with these 
examples (Decompressing- unpacking the meaning of equality and equality sign). Ayla asked the students the following: "I subtracted $1 \mathrm{~kg}$ from right hand side, $2 \mathrm{~kg}$ from left hand side. Will it be balanced?" For the concept of equality, she explained the students that "...it will give me equality now. When I subtracted from right, I need to subtract from the left to preserve the balance. You add to the right as much as you add to the left, and if you subtract from right, then you need to subtract from the left..." (CO-6/Equality and Equation). Likewise, Hale explained the concept of equality by using the state of balance in the scale (Bridging- making connections with arithmetic):

"The circles were $2 \mathrm{~kg}$ each. Then I added 2 and 2, it makes 4 . There are two squares [representing 1]. It is 5,6 . Then, we have $6 \mathrm{~kg}$ on the left side of the scale. I'm looking at the other side. The triangles were $3 \mathrm{~kg}$. How much did $3 \mathrm{~kg}$ plus $3 \mathrm{~kg}$ ? It is $6 \mathrm{~kg}$. The scale is in balance as each side has $6 \mathrm{~kg} . "$ (CO-5/Equality and Equation)

Even though teachers focused on relational thinking by using the balance scale, they did not use any symbolic representation (e.g., $2+2+1+1=3+3$ for the equality they modeled on balance scale. They made only verbal explanations through the scale model (SMK- knowledge of different types of representations and explanations) (Decompressing- unpacking the meaning of equality and equality sign and relationship between preserving the equality and relational thinking). Hence, the bridging between the model and the symbolic expression was implicit. (Bridging- making connections with arithmetic).

Likewise, none of the teachers used number sentences to emphasize the relational meaning of equality independent of the balance scale. (Decompressing- unpacking the relationship between preserving the equality and relational thinking). During the interviews, teachers were presented with an instructional scenario in which a teacher introduced the lesson about equality and the conservation of equality by using a number sentence (e.g., $8+4=\square+5$ ). While discussing the scenario, participating teachers did not focus on the relation between each side of the equality in the given number sentence. They were expected to focus on the concept that if one of the numbers increased (i.e., 4 becomes 5), then the other should decrease (i.e., 8 becomes 7) in order to preserve the equality. However, teachers pointed out that the purpose of using the number sentence could be helping students to "visualize the unknown" and facilitating the transition to use of symbols (SMK-knowledge of mathematical symbols, terms and different types of representations).

" $8+4=\square+5$, a question about transition to equation concept. The square was used and letters like $\mathrm{x}, \mathrm{y}, \mathrm{z}$ were not provided. It was visualized by using a square box, like in primary school subjects. When there is letters like $x, y$, the child has difficulties to see which number is represented, but when there is a box or square, it is easier for the child to see. This is why it is used, for visualization." (Hale, Interview III)

Understanding the structural properties of equations is related to comprehending the relational meaning of equal sign and the concept of equality. This becomes particularly important as students encounter and learn to solve algebraic equations with operations on both sides of the symbol (e.g., $3 x-5=2 x+1$ ) (Knuth et al., 2005). While teaching, bidirectional meaning of the equal sign needs to be stressed (Booth, 1988; Kieran, 1981; Knuth et al., 2005). The relational meaning of equality should not be expressed as a step-by-step process of solution for the equation, but it should be emphasized as a whole (Kieran, 1981).

In this study, participating teachers defined the concept of equation as "equality containing unknowns." They associated the concept of equation with letters, algebraic expressions and equations; and emphasized that equations include letters (unknown) and equality. Hale focused on the procedural aspects and defined equations as entities including unknowns and an equality. She did not use verbal expressions, problem situations or models representing an equation (Bridging- making clear and explicit the distinction between algebraic expression, equality and equation). Her explanation during the interview supported this. She said that "I often emphasize that if there is a letter and if there is equality, then it is an equation. It is already an equation when equality is added to the algebraic expression. We add equality to algebraic expressions." (Hale, Interview II) (SMK- knowledge of mathematical symbols and concepts). Likewise, Emre identified the equation by 
associating it with an algebraic expression. He stated that the difference of the equation from algebraic expressions is that equation contains equality. (Bridging- making clear and explicit the distinction between algebraic expression, equality and equation).

"The definition of the equation actually looks like algebraic expressions. But what were we saying in the algebraic expression, for example we say $3 x+2$, that is over. If we write a value equal to it $[3 x+2]$, then it is called an equation. So, what symbol is compulsory in the equation?" (CO5/Equality and Equation)

Emre did not make any clarification about how the letter symbols were defined in algebraic expressions and in equations. Nor he did clarify the meaning of equation (Decompressingunpacking the meaning of equation). His following explanation supported this: "There will be letters and operations in it. I always say in the class and repeat frequently. As the students know the algebraic expression, I will explain that equality will be added to the algebraic expression." (Emre, Interview II) Similar to Hale and Emre, Ayla also identified the equation by associating it with an algebraic expression. She compared the following equation, $3 x=3$ with the algebraic expressions; a. 3 and $x+2$ (Bridging- making clear and explicit the distinction between algebraic expression, equality and equation).

Ayla: Two more of a number, let's say this number as $x$. Two more of $x$ is $x+2$. Here is the difference between the two $(a .3, x+2$ and 3.x $=3)$. Can we find the value of $a$ and $x$ ?

Students: No.

Ayla: What should we do to be able to find $[x]$ ? Don't we need equality? Then we can solve it. We can find the value of the unknown. Then, equalities that contain unknowns are called equations. 3. $x=3$. Is there an unknown in it? Is there equality? If I express it this way, what are these? They are equations. What we do now is to solve the equations. (CO-6/Equality and Equation)

Ayla did not make a clear statement about how the letter symbols were defined in equations and in algebraic expressions. She determined that in algebraic expressions of $a .3$ and $x+2$, the value of a and $x$ cannot be found, but the value of unknown in 3. $x=3$ can be found because there exists an equality. She did not explicitly explain that algebraic letters can only take values that satisfy the given equation whereas letters in algebraic expressions can take any value (Decompressing- unpacking the meaning of equation and showing how to set up equations in detail (solve an equation means find the set of values that satisfy the given equation)).

Teachers also need to decompress algorithms for solving equations. In the present study, participating teachers explained algorithms for solving equations explicitly (SMK- knowledge of procedures). They made connections between combining similar terms and isolating the unknown by preserving the equality with the shortcut algorithm (i.e., moving terms to the other side of the equation and change the sign) (Decompressing-explaining the algorithms for solving equations). Ayla's explanation is presented below.

"Let's say we have $3 x+2=5$. Here moving +2 to the other side [of the equation] as -2 works because we are making the same change to each side so that the equation will be maintained. If we subtract 2 from each side [of the equation], 2 goes [referring $2-2=0$ ] here [left side of the equation] The right side [of the equation] becomes $5-2$. That means +2 [on the left side of the equation] is moved to the other side [right side of the equation] as -2 . We don't do like that all the time [referring the balance method] we use the shortcut of changing the sign." (Ayla, Interview II)

Teachers emphasized the balance method for solving equations in their instructional practices as well. Hale showed how students can solve the equation $x+3=8$ by doing the same operations on both side of the equation (Decompressing- recognizing different solutions for equations and the underlying concepts behind these solutions).

Hale: Here, we have $x+3=8$. What is my purpose? To find $x$. How can I find $x$ ? By isolating it. I would isolate $x$ if I move 3 here [to the left side of the equation]. Let's put -3 here [on the left side of the equation]. If we subtract 3 minus 3 , what do we have?

Students: 0. 
Hale: Ok, I take 3 from this side of the balance scale [referring to the left side of the equation]. Should I do anything here [referring to the right side of the equation]? What should I do?

Students: We'll subtract 3.

Hale: I will subtract 3 here [referring to the right side of the equation]. 3 minus 3 are 0.8 minus 3 are 5. $x=5$. (CO-6/Equality and Equation)

Teachers often used the balance scale model to show students that they had to preserve equality while solving equations. However, as observed in teaching the concept of equality, they did not make connections between actions on the models with symbolic expressions. Therefore, the bridging between the model and the corresponding mathematical representations became implicit (Bridging- making connections with arithmetic). As in the example below, Ayla showed students how to find the unknown weight by taking away $6 \mathrm{~kg}$ from each side of the scale. Even though she verbally explained her actions, she did not show it by setting the corresponding equation. She only wrote down the final equation $3 x=12$ and then solved the equation by using mathematical expression without referring to the balance scale anymore.

Ayla: Let me take away one square from both the right and the left side [of the balance scale]. Can I do that? Did I remove the same weight, right?

Students: Yes.

Ayla: Now, what do we have on the left side and on the right side? Let's write it down.

Tolga: We have $3 x^{\prime}$ s [referring to the left side of the scale]

Ayla: Because the scale is balanced, is the left side equal to the right side? They will be equal. What do we have on the right side?

Students: 2 squares.

Ayla: Each is $6 \mathrm{~kg}$, right? So, $3 \cdot x=12 \mathrm{~kg}$. What is the number that gives us 12 when multiplied by 3 ? Students: 4

Ayla: Then, $x$ should be $4 \mathrm{~kg}$. (CO-6/Equality and Equation)

\section{Discussion and Conclusion}

Teacher knowledge to enhance meaningful transition from arithmetic to algebra is particularly important in middle school mathematics. In order to develop a solid understanding of algebra, teachers need to unpack the meaning underlying basic concepts such as variable, algebraic expression and equation, make clear and explicit distinctions among concepts, and support their students in connecting these concepts with their prior knowledge and understanding in arithmetic. This study focused on three middle school mathematics teachers' content knowledge in practice as they introduced basic algebra concepts. Taking into account McCrory et al.'s (2012) work, the study examined how teachers used their knowledge of variable, algebraic expressions, equality, and equation in their teaching practices to decompress, trim and bridge. Interviews with the teachers and observations in the class revealed several instances where teachers decompressed the concepts and bridged them with each other or with students' early understandings. Trimming, on the other hand, was not observed during the participating teachers' common teaching practices, which will be discussed later.

Interviews and the class observations revealed that the participating teachers' conceptions of variable were rather shallow, which caused some constraints in regards to unpacking meaning in the classroom, as it has been suggested by literature (Asquith et al., 2007; Kieran, 1992). Even though the teachers were found to recognize and explain the distinctions between the various meanings of the concept of variable during the interview tasks, they did not explicitly focus on such differences in their instructional practices. They either implicitly mentioned the various meanings of the concept of variable or sent conflicting messages that restricted students' understanding. Using terms such as "unknown", "any value" or "variable" interchangeably may constrain students' understandings and access to different meanings and uses of algebraic letters. A similar case was also valid for algebraic expressions and equation. Participating teachers described algebraic expression and equation in terms of algebraic letters, operations, and symbols. This was evident in their responses to the interview tasks as well as in their teaching practices. For 
example, teachers explained algebraic expression as "an expression with at least one unknown and an operation". They either did not use or rarely used verbal expressions, problem situations or models to represent algebraic expressions. Even though they occasionally used the term "any value" to represent letters in algebraic expressions, the idea that "algebraic expressions are used for generalizations" often remained unexplained.

Teachers' attempts to decompress revealed their misunderstandings as well. For instance, they explained why algebraic letters are called as "variable" by stating that they take different values in different problems. Even though assuming the letter symbol b would take the same value in different problems is a common mistake, attributing the varying nature of variable to this is not a valid and acceptable explanation. Likewise, they used the object analogy for variable and described addition and subtraction in algebraic expressions using the fruit-salad approach (Booth, 1988). This result is consistent with the findings of the research conducted by Pomerantsev and Korosteleva (2003) with prospective teachers. This is also one of the most common misconceptions observed among students (Asquith et al., 2007; Booth, 1988; Blanton et al., 2017; Brizuela, 2016; Christo et al., 2007; MacGregor \& Stacey, 1997; Perso, 1992; Russell et al., 2009; Stacey \& MacGregor, 1997; Weinberg et al., 2016). Such analogies used by teachers may lead students to develop misconceptions that variables represent an object, not a numerical value and result in incorrect generalization of operations (Tirosh et al., 1988). While these instances demonstrated teachers' lack of content knowledge, it was also found that teachers assumed that the idea (i.e., different meanings of algebraic letters) was obvious and did not require further explanation. That is, they were unaware of the significance of such knowledge in developing a solid understanding of algebra. Hence, either teachers' lack of knowledge or their beliefs (e.g., "it is obvious") restricted them from decompressing important ideas behind the concepts of "variable" and "algebraic expression."

Equality is a concept that students are familiar based on their arithmetic experiences. Teachers decompressed the meaning of equality by making a common analogy with balance scale. Each participating teacher explained the concept of preserving equality when adding or subtracting objects (i.e., values) from each side of the balance scale. This was the case for teaching equations, as well. Teachers defined the concept of equation as "equality containing unknowns" and used balance scales in order to set and solve equations. Interestingly, even though they used several demonstrations with the balance scale, none of them made explicit connections between the actions on the scale with corresponding symbol representations. None of the teachers used number sentences to show equality and preserving the equality through number sentences. Supporting this evidence, teachers did not associate number sentences with relational thinking as well. Related to the teachers' limited knowledge about the relational meaning of the concept of equality, they did not establish a relationship with the value of both sides of the equality. Prior research conducted with teachers and prospective teachers also supported that finding, showing that they did not see number sentences as a tool for teaching equality and equation (Falkner et al., 1999; Knuth et al., 2008; Meyer, 2016; Stephens, 2006; Vermeluen \& Meyer, 2017). They were most successful in decompressing algorithms for solving equations and showing how equality is preserved when using the balance scale and when using symbolic representations separately. Participating teachers explained algorithms for solving equations explicitly. They made connections between combining similar terms and isolating the unknown by preserving the equality with the shortcut algorithm (i.e., move the terms to the other side of the equation and change the sign).

Effective bridging plays an essential role in the transition from arithmetic to algebra. Teachers can make meaningful transition to algebra by making clear and explicit distinctions between algebraic letters and letters used as labels of objects or abbreviated words that students are familiar in arithmetic. They can also bridge by emphasizing how algebraic expression, equality and equations are related to each other. Bridging was a commonly observed instructional practice among the participating teachers. The quality of bridging, however, did not always result in opportunities for meaningful transition. For instance, Ayla attempted to make connections with 
students' prior understanding by reminding the symbols (e.g., $\square, \Delta$, ?) used to represent the unknown in elementary school. Her attempt, however, provided a superficial transition because she did not make connections between the role they played in arithmetic and in algebra. Likewise, when teaching algebraic expressions, teachers sometimes made implicit connections with verbal statements. They did not make any connections with verbal problems or number patterns. Teachers' bridging among the concepts was also shallow. For instance, definitions focused on procedural aspects reduced the bridging between algebraic expressions and equations to the existence of the equality symbol. An expression was often judged to be an algebraic expression or equation by the presence or absence of a variable or letter, an operation and an equality symbol. These findings align with the limited conceptions of teachers revealed by early literature. For instance, Attorps (2003) determined that teachers explained the concept of equation more through operational processes and could not produce conceptual explanations about the meaning of the concept of equation. Even though teachers' use of balance scale could be considered as a good example for bridging the concept of relational thinking with equality and equation, lack of explicit connections between the model and the symbolic representations left this transition unexplored. Teachers did not make connections between basic algebraic concepts with their precursors such as relational thinking, which can be considered as a foundation for learning algebra (Carraher \& Schliemann, 2007). None of the teachers used number sentences to emphasize the relational meaning of equality or equation independent of the balance scale. Hence, the ideas such that "unknowns in an equation are the values that satisfy the given equation" or "letter symbols in algebraic expressions represent any values" were unexplored. These instances demonstrate the missing opportunities for making a good transition from students' pre-algebraic understandings.

The findings of the study also showed that trimming was not a common practice for the participating teachers. Focusing on only one of the meanings of algebraic letters (e.g., unknown) while disregarding others (e.g., generalized numbers) could be considered as trimming while teaching the concept of variable. Likewise, taking into account the sets being worked (e.g., $\mathbb{N}, \mathbb{Z}, \mathbb{R}$ ) and asking students how it may affect the result when they work on algebraic expressions or equations (e.g., compare $3 n$ and $n+6$ if $(n \in \mathbb{N})$ or $(n \in \mathbb{Z})$ ) could also be considered as trimming when teaching equations. However, instances that teachers scaled up or down the concepts to facilitate students' understandings were not observed in the study. Findings also showed that even though participating teachers acknowledged the importance of algebra as a subject matter in middle school mathematics curriculum, there were no instances where they decompressed the usefulness of it.

\section{Recommendations}

Lack of teachers' content knowledge negatively affects the pedagogical content knowledge and thus teaching practices (Ball, 1990; Charalambous et al., 2020; Copur-Gencturk, 2015, Hoover et al., 2016; Kelcey et al., 2019; Howell, 2012; McCrory et al., 2012; Stephens, 2004; Welder \& Simonsen, 2011). The findings of this study suggest that developing teachers' knowledge about algebra in practice is and should be an essential component of teacher professional development. Working on such practices could facilitate middle school mathematics teachers' recognition in regards to how algebraic concepts are related to each other as well as how they should be connected with students' early understandings in arithmetic.

Acknowledgements. This article is based on the first author's doctoral dissertation.

\section{References}

Asquith, P., Stephens, A. C., Knuth, E. J., \& Alibali, M. W. (2007). Middle school mathematics teachers' knowledge of students' understanding of core algebraic concepts: Equal sign and variable. Mathematical Thinking and Learning, 9(3), 249-272. https:/ / doi.org/10.1080/10986060701360910 
Attorps, I. (2003). Teachers' images of the 'equation' concept [Paper presentation]. Annual Conference of the International Group for the Psychology of Mathematics Education, Hiroshima, Japan.

Ball, D. L. (1990). The mathematical understandings that prospective teachers bring to teacher education. Elementary School Journal, 90(4), 449-446. https:// doi.org/10.1086/461626

Ball, D. L., Hill, H. C., \& Bass, H. (2005). Knowing mathematics for teaching: Who knows mathematics well enough to teach third grade, and how can we decide? American Educator, 29(1), 14-46.

Ball, D. B., Thames, M. H., \& Phelps, G. (2008). Content knowledge for teaching: What makes it special?. Journal of Teacher Education, 59(5), 389-407. https:// doi.org/10.1177/0022487108324554

Behr, M., Erlwanger, S., \& Nichols, E. (1980). How children view the equals sign. Mathematics Teaching, 92, 13-15.

Blanton, M., Brizuela, B. M., Gardiner, A. M., Sawrey, K., \& Newman-Owens, A. (2017). A progression in first-grade children's thinking about variable and variable notation in functional relationships. Educational Studies in Mathematics, 95(2), 181-202. https://doi.org/10.1007/s10649-016-97450

Blanton, M., Stephens, A., Knuth, E., Gardiner, A. M., Isler, I., \& Kim, J. S. (2015). The development of children's algebraic thinking: The impact of a comprehensive early algebra intervention in third grade. Journal for Research in Mathematics Education, 46(1), 39-87. https://doi.org/10.5951/jresematheduc.46.1.0039

Blanton, M., Otálora, Y., Brizuela, B. M., Gardiner, A. M., Sawyer, K. B., Gibbins, A., ve Kim, Y. (2018). Exploring kindergarten students' early understandings of the equal sign. Mathematical Thinking and Learning, 20(3), 167-201. https:/ / doi.org/10.1080/10986065.2018.1474534

Booth, L. (1988). Children's difficulties in beginning algebra. In A. F. Coxford \& A. P. Shulte (Eds.), The ideas of algebra, K-12 (pp. 20-32). National Council of Teachers of Mathematics.

Brizuela, B. M. (2016). Variables in elementary mathematics education. The Elementary School Journal, 117(1), 46-71. https://doi.org/10.1086/687810

Brizuela, B. M., Blanton, M., Sawrey, K., Newman-Owens, A., \& Murphy Gardiner, A. (2015). Children's use of variables and variable notation to represent their algebraic ideas. Mathematical Thinking and Learning, 17(1), 34-63. https:/ / doi.org/10.1080/10986065.2015.981939

Carraher, D. W., \& Schliemann, A. D. (2007). Early algebra and algebra reasoning. In F. Lester (Eds.), Second handbook of research on mathematics teaching and learning: A project of the National Council of Teachers of Mathematics (pp. 699-705). Information Age Publishing.

Caswell, L. M. (2009). The algebra content knowledge of beginning teachers in California [Unpublished doctoral dissertation]. Capella University, United States.

Charalambous, C. Y., Hill, H. C., Chin, M. J., \& McGinn, D. (2020). Mathematical content knowledge and knowledge for teaching: exploring their distinguishability and contribution to student learning. Journal of Mathematics Teacher Education, 23(6), 579-613. https://doi.org/10.1007/s10857-019-09443-2 [ŞD11]

Christou, K. P., \& Vosniadou, S. (2012). What kinds of numbers do students assign to literal symbols? Aspects of the transition from arithmetic to algebra. Mathematical Thinking and Learning, 14(1), 1-27. https://doi.org/10.1080/10986065.2012.625074

Christou, K.P., Vosniadou, S. \& Vamvakoussi, X. (2007). Students' interpretations of literal symbols in algebra. In S., Vosniadou, A. Baltas \& X. Vamvakoussi, (Eds.), Re- Framing the Conceptual Change Approach in Learning and Instruction (pp.285-299). Elsevier.

Copur-Gencturk, Y. (2015). The effects of changes in mathematical knowledge on teaching: A longitudinal study of teachers' knowledge and instruction. Journal for Research in Mathematics Education, 46(3), 280-330. https:// doi.org/10.5951/jresematheduc.46.3.0280

Creswell, J. W. (2007). Qualitative inquiry and research design: Choosing among five approaches. Sage.

Güler, M. \& Çelik, D. (2018). Uncovering the relation between CK and PCK: An investigation of preservice elementary mathematics teachers' algebra teaching knowledge. Journal of Research in Mathematics Education, 7(2), 162-194. https:// doi.org/10.17583/redimat.2018.2575

Denzin, N. \& Lincoln, Y. (2000). Introduction: The discipline and practice of qualitative research. In N. Denzin \& Y. Lincoln (Eds.). Handbook of qualitative reseacrh (pp. 1-28). Sage Publications.

Dooren, V. D., Verschaffel, L., \& Onghena, P (2002). The impact of preservice teachers' content knowledge on their evaluation of students' strategies for solving arithmetic and algebra word problems. Journal of Research in Mathematics Education, 33(5), 319-351. https:// doi.org/10.2307/4149957 
Even, R. (1993). Subject matter knowledge and pedagogical content knowledge: Prospective secondary teachers and the functions concepts. Journal for Reseacrh in Mathematics Education, 24, 94-116. https://doi.org/10.5951/jresematheduc.24.2.0094

Falkner, K.P., Levi, L., \& Carpenter, T. P. (1999). Children's understanding of equality: A foundation for algebra. Teaching Children Mathematics, 6, 231-236. https://doi.org/10.5951/TCM.6.4.0232

Herscovics, N., \& Linchevski, L. (1994). A cognitive gap between arithmetic and algebra. Educational Studies in Mathematics, 27(1), 59-78. https:// doi.org/10.1007/BF01284528

Hill, H. C., \& Ball, D. L. (2004). Learning mathematics for teaching: Results from California's Mathematics Professional Development Institutes. Journal for Research in Mathematics Education, 35(5), 330-351. https:// doi.org/10.2307/30034819

Hill, H. C., Ball, D. L., \& Schilling, S. G. (2008). Unpacking pedagogical content knowledge: conceptualizing and measuring teachers' topic-specific knowledge of students. Journal of Research in Mathematics Education, 39(4), 372-400. https://doi.org/10.5951/jresematheduc.39.4.0372

Hoover, M., Mosvold, R., Ball, D. L., \& Lai, Y. (2016). Making progress on mathematical knowledge for teaching. The Mathematics Enthusiast, 13(1), 3-34. https://doi.org/10.54870/1551-3440.1363

Howell, H. (2012). Characterizing mathematical knowledge for secondary teaching: A case from high school algebra [Unpublished doctoral dissertation]. New York University, United States.

Huang, R., \& Kulm, G. (2012). Prospective middle grade mathematics teachers' knowledge of algebra teaching. The Journal of Mathematical Behavior, 31, 417-430. https://doi.org/10.1016/j.jmathb.2012.06.001

Kelcey, B., Hill, H. C., \& Chin, M. J. (2019). Teacher mathematical knowledge, instructional quality, and student outcomes: a multilevel quantile mediation analysis. School Effectiveness and School Improvement, 30(4), 398-431. https:// doi.org/10.1080/09243453.2019.1570944

Kieran, C. (1981). Concepts associated with the equality symbol. Educational Studies in Mathematics, 12, 317326. https://doi.org/10.1007/BF00311062

Kieran, C. (1992). The learning and teaching of school algebra. In D. A. Grouws (Eds.), Handbook of research on mathematics teaching and learning (pp. 390-419). Macmillan.

Knuth, E. J., Alibali, M. W., McNeil, N.M., Weinberg, A., \& Stephens, A.C. (2005). Middle school students' understanding of core algebraic concepts: Equivalence \& Variable. Zentralblatt für Didaktik der Mathematik, 37(1), 68-76.

Knuth, E. J., Alibali, M. W., Hattikudur, S., McNeil, N.M., Weinberg, A., \& Stephens, A.C. (2008). The importance of equal sign understanding in the middle grades. Mathematics Teaching in the Middle School, 13(9), 514-519. https://doi.org/10.5951/MTMS.13.9.0514

Knuth, E., Stephens, A., Blanton, M., \& Gardiner, A. (2016). Build an early foundation for algebra success. Phi Delta Kappan, 97(6), 65-68. https://doi.org/10.1177/0031721716636877

Kuchemann, D. (1978). Children's understanding of numerical variables. Mathematics in School, 7(4), 23-26.

$\mathrm{Li}, \mathrm{X}$. (2007). An investigation of secondary school algebra teachers' mathematical knowledfe for teaching algebraic equation solving [Unpublished doctoral dissertation]. The University of Texas, Austin, United States.

MacGregor, M., \& Stacey, K. (1997). Students' understanding of algebraic notation: 11-15. Educational Studies in Mathematics, 33, 1-19. https:// doi.org/10.1023/ A:1002970913563

Malisani, E., \& Spagnolo, F. (2009). From arithmetical thought to algebraic thought: The role of variable. Educational Studies in Mathematics, 71, 19-41. https://doi.org/10.1007/s10649-008-9157-x

Matz, M. (1980). Towards a computational theory of algebraic competence. Journal of Mathematical Behavior, 3(1), 93-166.

McCrory, R., Floden, R., Ferrini-Mundy, J., Reckase, M. D., \& Senk, L. (2012). Knowledge of algebra for teaching: A framework of knowledge and practices. Journal for Research in Mathematics Education, 43(5), 584-615. https://doi.org/10.5951/jresematheduc.43.5.0584

Meyer, B. C. (2016). The equal sign: Teachers' specialised content knowledge and learners' misconceptions [Unpublished doctoral dissertation]. Cape Peninsula University of Technology.

Perso, T. (1992). Overcoming misconceptions in algebra: using diagnostic (conflict) teaching. Mathematical Association of Western Australia.

Philipp, R. (1992). The many uses of algebraic variables. Mathematics Teacher, 85, 557-561. https://doi.org/10.5951/MT.85.7.0557

Pomerantsev, L., \& Korosteleva, O. (2003). Do prospective elementary and middle school teachers understand the structure of algebraic expressions? Issues in the Undergraduate Mathematics Preparation of School Teachers: The Journal, 1, 1-10. 
Reckase, M. D., McCrory, R., Floden, R. E., Ferrini-Mundy, J., \& Senk, S. L. (2015). A multidimensional assessment of teachers' knowledge of algebra for teaching: Developing an instrument and supporting valid inferences. Educational Assessment, 20(4), 249-267. https://doi.org/10.1080/10627197.2015.1093927

Russell, M., O'Dwyer, L. M., \& Miranda, H. (2009). Diagnosing students' misconceptions in algebra: Results from an experimental pilot study. Behavior Research Methods, 41(2), 414-424. https://doi.org/10.3758/BRM.41.2.414

Spangenberg, E. D. (2021). Manifesting of pedagogical content knowledge on trigonometry in teachers ${ }^{\text {ee }}$ practice. Journal of Pedagogical Research, 5(3), 135-163. https:/ / doi.org/10.33902/JPR.2021371325

Stacey, K., \& MacGregor, M. (1997). Ideas about symbolism that students bring to algebra. The Mathematics Teacher, 90(2), 110-113. https://doi.org/10.5951/MT.90.2.0110

Stephens, A. C. (2004). Preservice elementary teachers conceptions of algebra and algebraic equivalence [Unpublished doctoral dissertation]. Universtity of Wisconsin, Madison.

Stephens, A. C. (2006.) Equivalence and relational thinking: Preservice elementary teachers' awareness of opportunities and misconceptions. Journal of Mathematics Teacher Education, 9, 249-278. https:// doi.org/10.1007/s10857-006-9000-1

Stephens, A. C. (2008). What "counts" as algebra in the eyes of preservice elementary teachers?. Journal of Mathematical Behavior, 27, 33-47. https:// doi.org/10.1016/j.jmathb.2007.12.002

Stephens, A. C., Knuth, E. J., Blanton, M. L., Isler, I., Gardiner, A. M., \& Marum, T. (2013). Equation structure and the meaning of the equal sign: The impact of task selection in eliciting elementary students' understandings. The Journal of Mathematical Behavior, 32, 173-182. https://doi.org/10.1016/j.jmathb.2013.02.001

Stump, S. L., \& Bishop, J. (2002). Preservice elementary and middle school teachers' conceptions of algebra revealed through the use of exemplary curriculum materials. In D. S. Mewborn, P. Sztajn, D.Y. White, H. G. Wiegel, R. L. Bryant \& K. Nooney (Eds.), Proceedings of the twenty-fourth annual meeting of the international group for the psychology of mathematics education (pp. 1903-1914). ERIC.

Tchoshanov, M., Cruz, M. D., Huereca, K., Shakirova, K., Shakirova, L., \& Ibragimova, E. N. (2017). Examination of lower secondary mathematics teachers' content knowledge and its connection to students' performance. International Journal of Science and Mathematics Education, 15(4), 683-702. https://doi.org/10.1007/s10763-015-9703-9

Tirosh, D., Even, R., \& Robinson, N. (1998). Simplifying algebraic expressions: Teacher awareness and teaching approaches. Educational Studies in Mathematics, 35(1), 51-64. https:// doi.org/10.1023/A:1003011913153

Usiskin, Z. (1999). Conceptions of school algebra and uses variables. In B. Moses (Eds.), Algebraic Thinking, Grades K-12: Readings from NCTM's School-Based Journals and Other Publications (pp. 7-13). Natinoal Council of Teachers Mathematics.

Van de Walle, J. A., Karp, K. S. ve Bay-Williams, J. M. (2010). Elementary and middle school mathematics: Teaching developmentally (7th ed.). Pearson Education.

Vermeulen, C., \& Meyer, B. (2017). The equal sign: teachers' knowledge and students' misconceptions. African Journal of Research in Mathematics, Science and Technology Education, 21(2), 136-147. https:// doi.org/10.1080/18117295.2017.1321343

Wasserman, N. H. (2016). Abstract algebra for algebra teaching: Influencing school mathematics instruction. Canadian Journal of Science, Mathematics and Technology Education, 16(1), 28-47. https://doi.org/10.1080/14926156.2015.1093200

Watkins, J. D. (2018). Exploring the knowledge of algebra for teaching [Unpublished doctoral dissertation]. University of Louisville, Louisville, Kentucky.

Weinberg, A., Dresen, J., \& Slater, T. (2016). Students' understanding of algebraic notation: A semiotic systems perspective. The Journal of Mathematical Behavior, 43, 70-88. https:/ / doi.org/10.1016/j.jmathb.2016.06.001

Welder, R. M., \& Simonsen, L. M. (2011). Elementary teachers' mathematical knowledge for teaching prerequisite algebra concepts. Issues in the Undergraduate Mathematics Preparation of School Teachers, 1, 1-16.

Yin, R. K. (2009). Case study research: Design and methods. Sage. 